\title{
Common behavioral problems among patients with dementia attending in tertiary care hospitals in Dhaka city
}

\author{
Sadya Tarannum, ${ }^{1}$ Bushra Sultana, ${ }^{2}$ Sultana Algin, ${ }^{3}$ Atiqul Haq Majumder ${ }^{4}$ \\ ${ }^{1}$ Assistant Professor, Ashiyan Medical College and Hospital, Khilkhet, Dhaka, Bangladesh; ${ }^{2}$ Psychiatrist, \\ Dhaka, Bangladesh; ${ }^{3}$ Associate Professor, Department of Psychiatry, Bangabandhu Sheikh Mujib Medical \\ University; ${ }^{4}$ Doctoral Student, Department of Psychiatry, University of Oulu, Finland.
}

\section{Article info \\ Received: 26 July 2016 \\ Accepted : 15 Sept 2016 \\ Number of tables: 06 \\ Number of figures : 03 \\ Number of refs. : 13}

\section{Correspondence:}

Sadya Tarannum

Mobile:

+8802-01711884136

Email

terminus_light@yahoo.com

\begin{abstract}
Summary:
Elderly people are increasing day by day both in developing and developed country due to development of new treatment, increased awareness of people and improved health facilities. This present study was conducted with the aim to identify behavioral problems according to severity of dementia. This descriptive cross sectional study was conducted in the Department of Psychiatry and Department of Neuro-medicine of Bangabandhu Sheikh Mujib Medical University (BSMMU), Dhaka, Bangladesh and in National Institute of Mental Health (NIMH), Sher-E-Bangla Nagar, Dhaka, Bangladesh from September 2013 to March 2015. A total 150 patients were selected purposefully; severity of dementia was graded according to Mini Mental State Examination (MMSE) and another questionnaire was applied to detect behavioral problems of patients. In this study mild dementia was found as the most frequent (38\%), followed by severe dementia (35.3\%) and moderate dementia (26.7\%). The results indicated that behavioral problem was more common in severe dementia. Behavioral problem was more common in severe dementia than in mild and moderate dementia. Among behavioral problems sleep disturbance and sexual disturbance were statistically significant This study provides information about pattern of behavioral problems among patients with dementia. Liaison approach with other discipline may improve quality of life of these patients treatable.
\end{abstract}

Bang J Psychiatry 2014,28(2):50-52

\section{Introduction}

Elderly people are increasing day by day both in developing and developed country due to development of new treatment, increased awareness and improved health facilities. With rapid increase in the number of elderly population and under the condition of socio-economic transformation, the elderly persons are experiencing a difficult time. Most of them are suffering from different types of psychiatric disorders. ${ }^{1}$ Patients with dementia need to adjust new life style which is stressful for them. Dementia reduces the ability to learn, reason, retain or recall past experience and there is also loss of memory, patterns of thoughts, feelings and activities. Behavioral problems include restlessness, agitation, sleep disturbances, eating difficulty, disinhibition and resistance to care. ${ }^{2}$ Behavioral and psychological symptoms are the non cognitive symptoms experienced in dementia. Non psychotic behavior associated with dementia includes aggression, wandering, eating disorder, sleep disturbance, sexual disturbance, resistance to care and lack of social behavior. ${ }^{3}$ Agitation 30 $70 \%$, wandering $15-40 \%{ }^{5}$ and sleep disturbances are common in $30-40 \%{ }^{4}$ of the patients with dementia. Behavioral and psychological symptoms of dementia
(BPSD), also known as neuropsychiatric symptoms, represented a group of non-cognitive symptoms and behavior. It is estimated that BPSD affect upto $90 \%$ of all dementia over the course of their illness. It is associated with poor outcomes, including distress among patients and caregivers, long-term hospitalization, misuse of medication, and increased health care costs. ${ }^{6}$ One study done in Pune, India showed that, psychological and behavioral symptoms were associated with dementia. Analysis of psychological symptoms showed that the commonest symptoms are irritability $(15.1 \%)$ followed by depression (5.8\%), agitation $(5.8 \%)$, poor sleep (5.2\%), hallucination $(4.7 \%)$, unconcern (4.1\%), anxiety (3.5\%), disinhibition (2.9\%), suspiciousness $(2.3 \%)$ and poor appetite $(2.3 \%){ }^{7}$ Behaviors such as aggression, screaming, restlessness, agitation and wandering are frequent reason for referral to specialist mental health services for older people. ${ }^{8}$ The lives of patients with dementia are severely disrupted because of the loss of memories of person, place, time, and circumstances and how to handle them. Some patients often have recent telephone conversations with people who have died some time ago. This sort of problem is likely to be a result of a misunderstanding of time. ${ }^{9}$ Considering 
this fact, present study was conducted with the aim to identify behavioral problems according to severity of dementia. Findings of this study will provide baseline information to stimulate further studies as well as be helpful for the development of awareness and improvement of quality of life of individuals in ageing society.

\section{Materials and methods}

This was a descriptive cross sectional study conducted among patients having dementia from September 2013 to March 2015 in the Department of Psychiatry and Department of Neuro-medicine of Bangabandhu Sheikh Mujib Medical University, Shahbag, Dhaka and National Institute of Mental Health, Sher-E-Bangla Nagar, Dhaka. Researcher took patients from dementia clinic of BSMMU and geriatric clinic of $\mathrm{NIMH}$ on their respective days and also from indoor and outdoor of respective institutes. A total number of 150 patients having the age range of 60 years and above irrespective of sex were selected purposefully and informed consent was taken from patient and their care givers or their legal guardians. Each case of severity of dementia was graded according to Mini Mental State Examination (MMSE) by the consultants of respective institutes. Another questionnaire was applied to detect behavioral problems of patients. Due to lack of validated tool in Bangladesh researcher herself formed this questionnaire to diagnose behavioral problem in patients with dementia. It included wandering, aggression, sleep disturbances, restlessness, eating disorder \& lack of social behavior. for Social Sciences (SPSS), version-15. Level of significance was measured at $95 \%$ confidence interval at $5 \%$ level of significance.

\section{Results}

According to MMSE among participants in this study mild dementia was found as the most frequent $(38 \%)$, followed by severe dementia $(35.3 \%)$ and moderate dementia (26.7\%) (Figure 1).

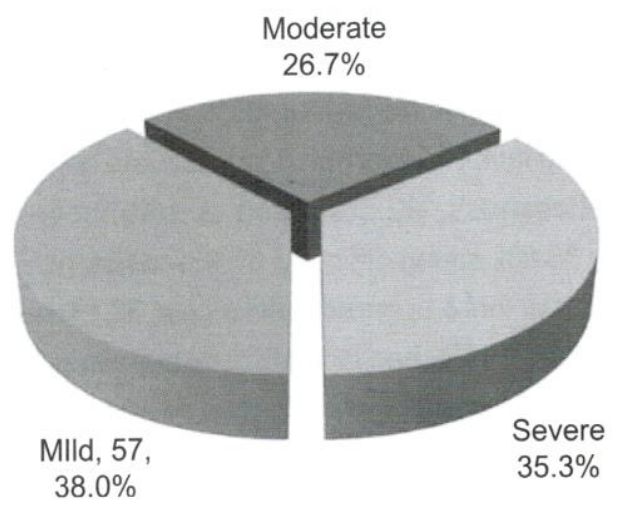

Figure 1: Types of dementia according to severity by MMSE $(n=150)$

Behavioral problem was more common in severe dementia than in mild and moderate dementia. Among behavioral problems sleep disturbance and sexual disturbance was statistically significant $(p<0.05)$ (Table 1).

Table 1: Behavioral problem by the types of dementia according to severity $(n=150)$

\begin{tabular}{|c|c|c|c|c|}
\hline \multirow[t]{2}{*}{ Behavioral problem } & \multicolumn{3}{|c|}{ Severity } & \multirow[t]{2}{*}{ p value* } \\
\hline & Mild & Moderate & Severe & \\
\hline Restlessness & $50(87.7)$ & $35(87.5)$ & $50(94.3)$ & 0.42 \\
\hline Sleep disturbances & $47(82.5)$ & $39(97.5)$ & $49(92.5)$ & $0.04^{*}$ \\
\hline Remaining in sleep & $12(25.5)$ & $10(25.6)$ & $13(26.5)$ & \\
\hline Early morning awakening & $17(36.2)$ & $15(38.5)$ & $15(30.6)$ & \\
\hline Difficulty falling in sleep & $12(25.5)$ & $11(28.2)$ & $14(28.6)$ & \\
\hline Increased sleep & $6(12.8)$ & $3(7.7)$ & $7(14.3)$ & \\
\hline Wandering & $32(56.1)$ & $23(57.5)$ & $37(69.8)$ & 0.28 \\
\hline Eating disorder & $45(78.9)$ & $33(82.5)$ & $46(86.8)$ & 0.55 \\
\hline Increased appetite & $5(11.1)$ & $1(3.0)$ & $3(6.5)$ & \\
\hline Decreased appetite & $40(88.9)$ & $32(97.0)$ & $43(93.5)$ & \\
\hline Does not allow care giver to take care & $33(57.9)$ & $20(50.0)$ & $36(67.9)$ & 0.21 \\
\hline Sudden aggressive behavior & $44(77.2)$ & $34(85.0)$ & $37(69.8)$ & 0.22 \\
\hline Sexual disturbance & $20(35.1)$ & $22(55.0)$ & $17(32.1)$ & $0.05^{\star}$ \\
\hline Decreased drive & $17(85.0)$ & $22(100.0)$ & $17(100.0)$ & \\
\hline Increased drive & $3(15.0)$ & $0(.0)$ & $0(.0)$ & \\
\hline Lack of social behaviour & $47(82.5)$ & $37(92.5)$ & $47(88.7)$ & 0.32 \\
\hline Others & $0(.0)$ & $1(2.5)$ & $2(3.8)$ & \\
\hline
\end{tabular}

*Signification association 


\section{Discussion}

Proportion of mild, moderate and severe dementia was almost same. No study was found about the prevalence of mild, moderate and severe dementia. Behavioral problem was common among patients suffering from dementia. Mild dementia had $87.7 \%$ restlessness, $82.5 \%$ sleep disturbances, $56.1 \%$ wandering, $78.95 \%$ eating difficulty, $57.9 \%$ resistance to care, $77.2 \%$ had sudden violent \& aggressive behavior $35.1 \%$ sexual disturbance and $82.5 \%$ had lack of social behaviour. Moderate dementia had $87.5 \%$ restless, $97.5 \%$ sleep disturbances, $57.5 \%$ wandering, $82.5 \%$ eating difficulty, $50 \%$ had resistance to care, $85 \%$ sudden violent and aggressive behaviour, 55\% sexual disturbances and $92.5 \%$ had lack of social behaviour. Severe dementia had $94.3 \%$ restlessness, $92.5 \%$ sleep disturbances, $69.8 \%$ wandering, $86.8 \%$ eating difficulty, $67.9 \%$ resistance to care, $69.8 \%$ sudden violent \& aggressive behaviour, $32.1 \%$ had sexual disturbance and $88.7 \%$ had lack of social behaviour. In above behavioral problems sleep disturbance was statistically significant. This result was similar to these studies where authors found that major depression decreased in severe stages, while agitation, aggression, and psychosis were more frequent in late stages. Anxiety, wandering, irritability, inappropriate behavior, uncooperativeness, emotional labiality associated with agitation, aggression, and psychosis, which found in severe dementia. ${ }^{10}$ It was clear that behavioral symptom was more common in severe dementia. Patients with severe dementia came with only complaints of behavioral problem. It was consistent with this study. Another study showed that, prevalence of sleep disturbance was $24.5 \%$ among mild to moderate Alzheimer's disease associated with other behavioral disturbances. ${ }^{11}$ It was not consistent with this study. Researcher found that demented patients usually slept at daytime, due to forgetfulness they usually failed to remember when they usually sleep. Sometimes caregivers did not notice when they usually sleep due to negligence. Demented people usually frequently complained about sleep disturbance. Sometimes demented people could not sleep properly due to association with other behavioral problems. Another study showed that anxiety was present up to $94.5 \%$ in vascular with severe dementia. In the other hand this study showed that in severe dementia agitation was present up to $55 \%$ of patents. ${ }^{12}$ So, this might be the cause of inconsistency. Anxiety $54 \%$, eating problem $28 \%$ and aberrant motor behavior $47 \%$ was found in patients with dementia in a study, done on 125 demented people and most of them already took anti-demented and other psychotropic. In this study most patients at the time of data collection did not take any medication. It was their first visit. So, this result was inconsistent with that study.

\section{Conclusion}

Despite a number of limitations (like small sample size, short duration of study, lack of data from caregivers, purposive. sampling, and lack of validated tool) this study provides information about pattern of behavioral problems among patients with dementia. The findings in this study emphasizes that more awareness is required regarding management of patients with dementia. Patients with dementia need specific treatment and management. Liaison approach with other discipline is needed for these patients. To increase the quality of life and to avoid treatment complication it is necessary to give a comprehensive management in this elderly group.

\section{References}

1. Ballard C, Neill D, O'Brien J, McKeith IG, Ince P, Perry R. Anxiety, depression and psychosis in vascular dementia: prevalence and associations. J Affect Disord 2000;59(2):97106.

2. Geddes J, Price J, MC Knight R. Delirium, dementia and other cognitive disorders. 4th ed. Oxford: Oxford Medical Publications; 2005. p.314.

3. Gelder M, Harisson P, Cowen P. Dementia, delirium \& otherneuro-psychiatric disorder. $5^{\text {th }}$ ed. New York: Oxford University Press; 2006. p. 331.

4. McCurry SM, Gibbons LE, Logsdon RG, Teri L. Anxiety and nighttime behavioral and disturbances. Awakening in patients with A|zheimer's disease. J Gerontol Nurs 2004;30(1):12-20.

5. Holtzer R, Tang MX, Devanand DP, Steven M, Domonick J, Marder $\mathrm{K}$, et al. Psychopharmacological features in Alzheimer's disease, course and relationship with cognitive status. J Am Geriatr Soc 2003;51(7):953-60.

6. Cerejeira J, Lagarto L, Ladinsha MEB. Behavioral and psychological symptoms of dementia. Front Neurol 2012;73(3).

7. Saldhana D, Mani RM, Srivastava K, Goyal S, Bhattacharya D. An epidemiological study of dementia under the aegis of mental health programe, Maharashtra, Pune chapter. Indian J Psychiatry 2010;52(2):131-9.

8. Turne S. Behavioural symptoms of dementia in residential settings: A selective review of non-pharmacological interventions. Aging Ment Health 2005;9(2):93-104.

9. Fetveit A. Late life insomnia a review. Geriatr Gerontol Int 2009;9(3):220-34

10. Lopez OL, Becher JT, Sweet RA, Klunk W, Kaufer DI, Saxton J, et al. Psychiatric symptoms vary with the severity of dementia in probable Alzheimer's disease. J Neuropsychiatry Clin Neurosci 2003;15(3):346-53.

11. Moran M, Lynch CA, Walsh C, Coen R, Coakley D, Lavlar BA. Sleep disturbance in mild to moderate Alzheimer's disease. Sleep Med 2005;6(4):347-52.

12. Fuh, JL, Liu CK, Mega MS, Wang S, Cummings JL. Behavioral disorders and care givers reaction in Taiwanese patients with AD. Int Psycho geriatr 2001;13(1):121-8.

13. Gracia AJM, Lara JP, Cruz B, Garrido V, Gris E, Barbancho MA. Sleep disturbances in Alzheimer's disease are associated with neuropsychiatric symptoms and antidementia treatment. J Nerv Ment Dis 2013;201(3):251-7. 